\title{
Synthesis of mesoporous Co/Ce-SBA-15 materials and their catalytic performance in the catalytic oxidation of benzene
}

\author{
Zhen $\mathrm{Mu}^{\mathrm{a}}$, Jin Jun $\mathrm{Li}^{\mathrm{a}}$, Hua Tian ${ }^{\mathrm{a}}$, Zheng Ping Hao ${ }^{\mathrm{a}, *}$, Shi Zhang Qiao ${ }^{\mathrm{b}, * *}$ \\ ${ }^{a}$ Research Center for Eco-Environmental Sciences, Chinese Academy of Sciences, Beijing 100085, PR China \\ ${ }^{\mathrm{b}}$ Australian Research Council (ARC) Centre for Functional Nanomaterials, School of Engineering, \\ The University of Queensland, Brisbane, QLD 4072, Australia
}

Received 13 July 2007; received in revised form 17 October 2007; accepted 30 October 2007

Available online 7 November 2007

\begin{abstract}
Cerium-containing SBA-15 mesoporous materials, with different $\mathrm{Ce} / \mathrm{Si}$ molar ratios, were synthesized by a direct hydrothermal synthesis method and further modified by impregnation with 10, 15 and $20 \mathrm{wt}$ \% Co. Characterizations by powder X-ray diffraction (XRD), $\mathrm{N}_{2}$ sorption, inductively coupled plasma (ICP) and UV-vis spectroscopy were carried out. The small-angle XRD and $\mathrm{N}_{2}$ sorption characterizations showed that these Co supported materials have less-ordered mesoporous structures with partial blockage of pores, and their specific surface area, pore volume and pore size were relatively lower than those of unsupported ceriumcontaining SBA-15. Spinel $\mathrm{Co}_{3} \mathrm{O}_{4}$ constituted the predominant cobalt phase in the prepared catalysts, and $\mathrm{CeO}_{2}$ was also detected. All the Co supported catalysts exhibited high catalytic activity in the oxidation of benzene.
\end{abstract}

(C) 2007 Elsevier Ltd. All rights reserved.

Keywords: A. Metals; A. Oxides; B. Chemical synthesis; D. Catalytic properties

\section{Introduction}

Periodic mesoporous materials have been widely explored as supports for preparing Co supported catalysts [1-8]. The high surface area and uniform pore-size distribution of mesoporous molecular sieves facilitate the development of higher metal dispersions and better control on the cobalt particle size. Among many kind of mesoporous silicas such as MCM-41, MSU, FSM-16 and SBA-15, etc., SBA-15 has attracted much more attention and been used as support in many catalytic reactions owing to its higher surface area $\left(600-1000 \mathrm{~m}^{2} / \mathrm{g}\right)$ and larger pore diameter ranging from 5 to $30 \mathrm{~nm}[9,10]$. Recently, Co supported SBA-15 was prepared and proven to be an effective catalyst for the CO oxidation [4], removal of volatile organic compounds [5] and the Fischer-Tropsch synthesis of hydrocarbons [6-8]. However, studies on the catalytic performance of $\mathrm{M}-\mathrm{Co}(\mathrm{M}=$ metallic element $)$ bimetallic system supported on a mesoporous surface are very limited [2,11].

Cerium-containing materials are powerful one-electron oxidants [12]. Existence of different sites of cerium ions may be important for catalytic activity [13]. Ceria has been widely used as a direct support material or an additive in many oxidation catalysts because of its low temperature reducibility, oxygen storage and release properties. These

\footnotetext{
* Corresponding author. Tel.: +8610 62849194; fax: +861062923564.

** Corresponding author. Tel.: +61 733463815 ; fax: +61 733656074 .

E-mail addresses: zpinghao@rcees.ac.cn (Z.P. Hao), s.qiao@uq.edu.au (S.Z. Qiao).
} 
ceria-containing catalysts have been studied in the oxidation of CO [14], water-gas shift reactions [15], elimination of $\mathrm{CO}$ and $\mathrm{NO}_{x}$ contaminants from automotive exhaust gases and combustion of hydrocarbons [16].

In a recent work, we synthesized cerium-containing SBA-15 materials by the direct hydrothermal method [9]. These materials possessed the typical hexagonal structure of SBA-15 and displayed a large pore diameter with uniform pore size distribution [9]. It was also observed that the application of the direct hydrothermal method favored the dispersion of $\mathrm{CeO}_{2}$ on SBA-15, to a greater extent, than the traditional impregnation method—an observation that has been previously reported [17]. Furthermore, these cerium-containing SBA-15 materials have a higher specific surface area than SBA-15 [18]. Thus, it can be predicted that the combination of cobalt with cerium-containing SBA-15 will lead to a good catalytic performance. However, to the best of our knowledge, there has been no published work, on the utilization of cerium-containing SBA-15 as a catalyst support material.

In this study, highly ordered cerium-containing SBA-15 mesoporous materials were synthesized and used as a support to prepare cobalt/cerium bimetallic catalysts. All catalysts were characterized by powder X-ray diffraction (XRD), $\mathrm{N}_{2}$ sorption, UV-vis spectra analysis and inductively coupled plasma (ICP) analysis. Their catalytic activity was investigated by the catalytic deep oxidation of benzene.

\section{Experimental}

Cerium-containing SBA-15 materials were synthesized using tetraethyl-orthosilicate (TEOS) and cerium nitrate $\left(\mathrm{Ce}\left(\mathrm{NO}_{3}\right)_{3} \cdot 6 \mathrm{H}_{2} \mathrm{O}\right)$ as the silicon and cerium precursors respectively. Nonionic triblock copolymer surfactant $\mathrm{EO}_{20} \mathrm{PO}_{70} \mathrm{EO}_{20}(\mathrm{P} 123$, Aldrich) was used as the structure-directing agent. Concentrated aqueous $\mathrm{HCl}$ solution was used as the acid source.

Cerium-containing SBA-15 was synthesized as follows: $1 \mathrm{~g}$ of P123 was dissolved in $35 \mathrm{ml}$ of aqueous $\mathrm{HCl}$ solution at $\mathrm{pH} 2.0$, then a certain amount of cerium nitrates was added, followed by the addition of $2.3 \mathrm{ml}$ TEOS and a certain amount of $\mathrm{NH}_{4} \mathrm{~F}(\mathrm{~F} / \mathrm{Si}=0.03)$. After stirring at $35^{\circ} \mathrm{C}$ for $24 \mathrm{~h}$, the mixture was transferred into an autoclave and aged at $100{ }^{\circ} \mathrm{C}$ for $48 \mathrm{~h}$. The resultant solid was filtered and dried at $100{ }^{\circ} \mathrm{C}$ for $24 \mathrm{~h}$. The mesoporous samples were finally obtained after calcination at $550{ }^{\circ} \mathrm{C}$ for $6 \mathrm{~h}$. The percentage of cerium present was 8,15 and $25 \%$ and expressed as the weight ratio of $W_{\text {cerium }} / W_{\mathrm{Ce}-\mathrm{SBA}-15}$. These samples were noted as $y$ Ce-SBA- 15 , where $y$ is the cerium content (wt.\%) in the Ce-SBA-15.

The cobalt-loaded Ce-SBA-15 was prepared by the wetness impregnation technique. Different amounts of cobalt nitrate hydrate $\left(\mathrm{Co}\left(\mathrm{NO}_{3}\right)_{2} \cdot 6 \mathrm{H}_{2} \mathrm{O}\right)$ were dissolved in $10 \mathrm{ml}$ of ethanol, mixed with $0.5 \mathrm{~g}$ of Ce-SBA-15, and evaporated at $60{ }^{\circ} \mathrm{C}$. These products were finally calcined at $500{ }^{\circ} \mathrm{C}$ for $4 \mathrm{~h}$ in static air for the decomposition of impregnated salt to cobalt oxide. The percentage of cobalt tested was 10,15 and 20\% and expressed as the weight ratio of $W_{\text {cobalt }} /$ $\left(W_{\text {cobalt }}+W_{\text {Ce-SBA-15 }}\right)$. The samples were noted as Co- $x / y$ Ce-SBA-15, where $x$ represents the cobalt loading (wt. $\left.\%\right)$.

To study the effect of different supporting materials on catalytic performance, $\mathrm{CeO}_{2} / \mathrm{SBA}-15$ and $\mathrm{CeO}_{2} / \mathrm{Al}_{2} \mathrm{O}_{3}$, which were prepared by the wetness impregnation method, were also developed to load Co. Using $\mathrm{Ce}\left(\mathrm{NO}_{3}\right)_{3} \cdot 6 \mathrm{H}_{2} \mathrm{O}$ as the precursor, Ce was firstly loaded on SBA-15 (BET area, $662 \mathrm{~m}^{2} / \mathrm{g}$ ) and $\mathrm{Al}_{2} \mathrm{O}_{3}\left(148 \mathrm{~m}^{2} / \mathrm{g}\right)$. These cerium-containing materials were then used as supports to prepare $\mathrm{Co} / \mathrm{CeO}_{2} / \mathrm{SBA}-15$ and $\mathrm{Co} / \mathrm{CeO}_{2} / \mathrm{Al}_{2} \mathrm{O}_{3}$ catalysts by loading $\mathrm{Co}$ through the use of a similar method to the one mentioned above. The cerium and cobalt content in these catalysts was 8 and $10 \mathrm{wt} . \%$, which is similar to that of the Co-10/8Ce-SBA-15 sample.

The metal content in the catalysts was determined by ICP (OPTIMA 2000). Before any measurements were taken, the solid sample was dissolved in dilute $\mathrm{HNO}_{3}$ solution with a small amount of HF. Wide-angle XRD patterns were measured on a Rigaku powder diffractometer (D/MAX-RB) using $\mathrm{Cu} K \alpha$ radiation $(\lambda=0.15418 \mathrm{~nm})$ in the $2 \theta$ range of $10-70^{\circ}$ with a scanning rate of $4^{\circ} \mathrm{min}^{-1}$. Small-angle XRD was recorded on a SIEMENS D5005D powder diffraction system using $\mathrm{Cu} K \alpha$ radiation in the $2 \theta$ range of $0.7-6.0^{\circ}$ with a scanning step size of $0.02^{\circ}$. The textural properties of the samples were measured by $\mathrm{N}_{2}$ sorption at liquid $\mathrm{N}_{2}$ temperature, using a gas adsorption analyzer NOVA 1200. The diffuse reflectance UV-vis spectra were collected on a HITACHI UV3000 scanning spectrophotometer from 190 to $800 \mathrm{~nm}$. The powder sample was loaded into a quartz cell and $\mathrm{BaSO}_{4}$ was used as reference.

The catalytic activity was investigated in a fixed bed reactor and the temperature of catalyst bed was measured by a thermocouple. To create the stream containing benzene, one stream of pure air was passed through a boat-shaped saturator in an ice bath to produce a mixed gas containing benzene of high concentration, which was further diluted, with another stream of pure air before reaching the reaction bed. The total flow rate was set to be $320 \mathrm{ml} \mathrm{min}^{-1}$ with 
the concentration of ca. 1000 ppm by adjusting the two flows. In each run, $300 \mathrm{mg}$ of catalyst with 40-60 meshes was tested. The gas hourly space velocity (GHSV) in the tests was kept ca. 39,600 $\mathrm{h}^{-1}$. An on-line gas chromatograph (GC) equipped with a FID detector was used to analyze the concentration of benzene in the inlet and outlet gas.

\section{Results and discussions}

\subsection{Structural characterization of $\mathrm{Co} / \mathrm{Ce}-\mathrm{SBA}-15$ catalysts}

Fig. 1 displays the small-angle XRD patterns of 8Ce-SBA- 15 and Co- $x / 8 \mathrm{Ce}-\mathrm{SBA}-15$ catalysts. Three well-resolved diffraction peaks of 8Ce-SBA-15, indexed as the $\left(\begin{array}{lll}1 & 0 & 0\end{array}\right),\left(\begin{array}{lll}1 & 1 & 0\end{array}\right),\left(\begin{array}{lll}2 & 0 & 0\end{array}\right)$ diffractions, reflect the two-dimensional hexagonal mesostructure with a space group of $p 6 \mathrm{~mm}$ symmetry [9]. After being impregnated, the intensity of the characteristic reflection peaks of $\mathrm{Co}-x / 8 \mathrm{Ce}-\mathrm{SBA}-15$ is found to be reduced, indicating the loss of long-range order. This may be attributed to the symmetry destroyed by the Co species, which was also found in the ordered mesoporous silica loading with guest matter. This is evident by the decreased diffraction contrast [19]. Furthermore, the prominent peak $\left(\begin{array}{lll}1 & 0 & 0\end{array}\right)$ of Co- $x / 8 \mathrm{Ce}-\mathrm{SBA}-15$ shifts to lower angles compared with 8Ce-SBA-15. The unit-cell parameters $\left(a_{0}\right)$ of cobalt-supported catalysts are provided in Table 1. It can be observed that the $a_{0}$ of all the Co- $x / 8 \mathrm{Ce}-\mathrm{SBA}-15$ (ca. $11.6-$ $11.8 \mathrm{~nm})$ is larger than that of 8Ce-SBA-15 $(11.42 \mathrm{~nm})$. This may be ascribed to the partial incorporation of cobalt into the framework of 8Ce-SBA-15 [20].

The wide-angle XRD patterns of the catalysts are shown in Fig. 2. In all prepared catalysts, the cobalt was present in the form of spinel $\mathrm{Co}_{3} \mathrm{O}_{4}$ (JCPDS file No. 9-0418). The characteristic peaks of Co- $x / 8 \mathrm{Ce}-\mathrm{SBA}-15$ become narrow and sharp with an increase in cobalt loading, indicating an increase of the mean $\mathrm{Co}_{3} \mathrm{O}_{4}$ crystallite size. There is no obvious difference of $\mathrm{Co}_{3} \mathrm{O}_{4}$ characteristic peaks for Co-20/yCe-SBA-15 catalysts, except for a slight increase in the mean $\mathrm{Co}_{3} \mathrm{O}_{4}$ crystallite size with the increase of $\mathrm{Ce}$ content in the support. The crystallite size of $\mathrm{Co}_{3} \mathrm{O}_{4}$ was calculated from the line broadening of the most intense XRD reflections, using the Scherrer equation [21], and shown in Table 1. For all the catalysts, the mean $\mathrm{Co}_{3} \mathrm{O}_{4}$ crystallite size was in the range of 2.3-10.9 nm, which was smaller than that of bulk $\mathrm{Co}_{3} \mathrm{O}_{4}$ reported in our previous work [4]. This indicates that $\mathrm{Co}_{3} \mathrm{O}_{4}$ was well dispersed on the surface of $y$ Ce-SBA-15 but its crystallite size increases with increasing cobalt loading. Besides the detection of $\mathrm{Co}_{3} \mathrm{O}_{4}$ spinel phase, the characteristic diffraction peaks of $\mathrm{CeO}_{2}$ fluorite structure at $2 \theta=28.5,33.3,47.5$ and $56.4^{\circ}$ are clearly observed for all

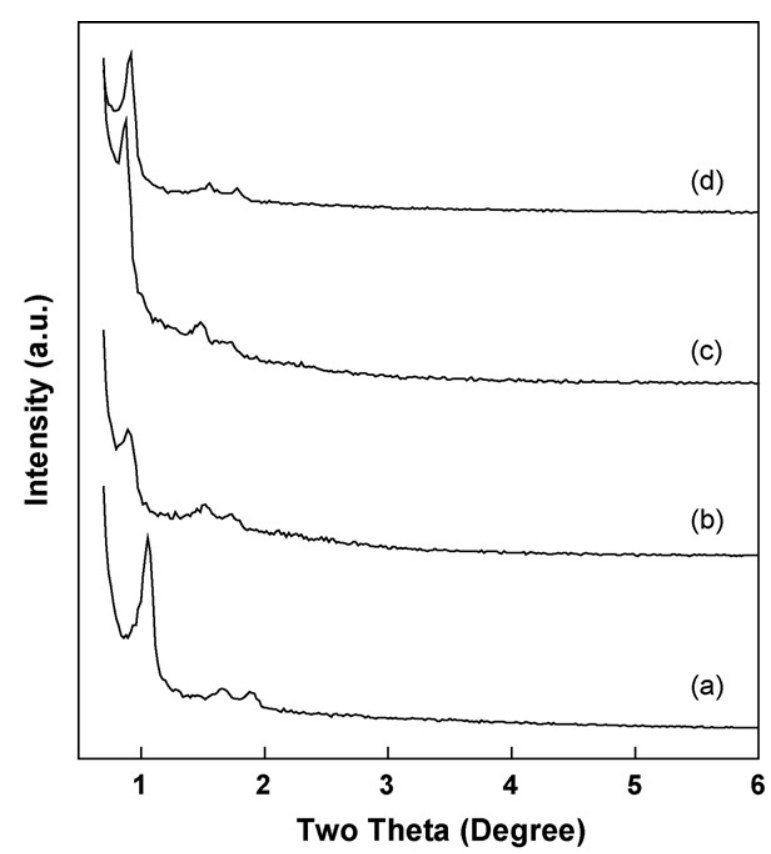

Fig. 1. SAXRD patterns of (a) 8Ce-SBA-15, and its modified catalysts with different cobalt loadings: (b) $10 \%$, (c) $15 \%$ and (d) $20 \%$. 
Table 1

Physico-chemical property of catalysts

\begin{tabular}{|c|c|c|c|c|c|c|c|}
\hline Catalysts & Co content $(\%)$ & $a_{0}^{\mathrm{a}}(\mathrm{nm})$ & $S_{\mathrm{BET}}{ }^{\mathrm{b}}\left(\mathrm{m}^{2} / \mathrm{g}\right)$ & $V_{\mathrm{p}}^{\mathrm{c}}\left(\mathrm{cm}^{3} / \mathrm{g}\right)$ & $D_{\mathrm{p}}^{\mathrm{d}}(\mathrm{nm})$ & $w^{\mathrm{e}}(\mathrm{nm})$ & $d_{\left(\mathrm{Co}_{3} \mathrm{O}_{4}\right)}(\mathrm{nm})$ \\
\hline 25Ce-SBA-15 & - & 11.52 & 797.23 & 1.1 & 6.5 & 5.02 & - \\
\hline 15Ce-SBA-15 & - & 11.45 & 864.46 & 1.2 & 6.6 & 4.85 & - \\
\hline 8Ce-SBA-15 & - & 11.42 & 912.26 & 1.2 & 6.6 & 4.82 & - \\
\hline $\mathrm{CeO}_{2} / \mathrm{SBA}-15$ & - & - & 594.33 & 0.78 & 5.8 & - & - \\
\hline $\mathrm{CeO}_{2} / \mathrm{Al}_{2} \mathrm{O}_{3}$ & - & - & 113 & 0.31 & 10.4 & & \\
\hline Co-20/25Ce-SBA- 15 & 19.7 & 11.62 & 452.10 & 0.58 & 5.28 & 6.34 & 10.9 \\
\hline Co-20/15Ce-SBA-15 & 19.6 & 11.68 & 495.97 & 0.59 & 5.01 & 6.67 & 10.7 \\
\hline Co-20/8Ce-SBA-15 & 19.6 & 11.63 & 529.99 & 0.63 & 4.59 & 7.04 & 10.6 \\
\hline Co-15/8Ce-SBA-15 & 14.6 & 11.81 & 556.22 & 0.67 & 4.52 & 7.29 & 6.2 \\
\hline Co-10/8Ce-SBA-15 & 9.2 & 11.58 & 584.37 & 0.72 & 4.36 & 7.22 & 2.3 \\
\hline $\mathrm{Co} / \mathrm{CeO}_{2} / \mathrm{SBA}-15$ & 9.4 & - & 418.26 & 0.43 & 4.29 & - & - \\
\hline $\mathrm{Co} / \mathrm{CeO}_{2} / \mathrm{Al}_{2} \mathrm{O}_{3}$ & 9.2 & - & 86 & 0.21 & 8.7 & - & - \\
\hline
\end{tabular}

${ }^{\mathrm{a}} a_{0}$ calculated by $d_{100}, a_{0}=2 \times d_{100} / \sqrt{3}$.

b BET specific surface areas.

c Total pore volumes were obtained at $P / P_{0}=0.99$.

d Average pore diameters.

e Pore wall thickness $=a_{0}-D_{\mathrm{p}}$.

the catalysts. However, there is no other significant diffraction peak found, therefore, it is difficult to identify the existence of the $\mathrm{Co}-\mathrm{Ce}-\mathrm{O}$ compound.

Fig. 3 displays the adsorption/desorption isotherms of Co- $x / 8 \mathrm{Ce}-\mathrm{SBA}-15$ and $8 \mathrm{Ce}-\mathrm{SBA}-15$ materials. For all samples, the isotherms were of type IV according to the IUPAC classification of adsorption isotherms [22], which is a typical characteristic of mesoporous materials. However, it is easy to observe that the hysteresis loops of Co- $x / 8 \mathrm{Ce}-$ SBA-15 become broader than those of 8Ce-SBA-15. The desorption branch of the isotherm shifts to lower pressure, whereas the adsorption branch is not significantly changed. As suggested by Ravikovitch and Neimark [23], this

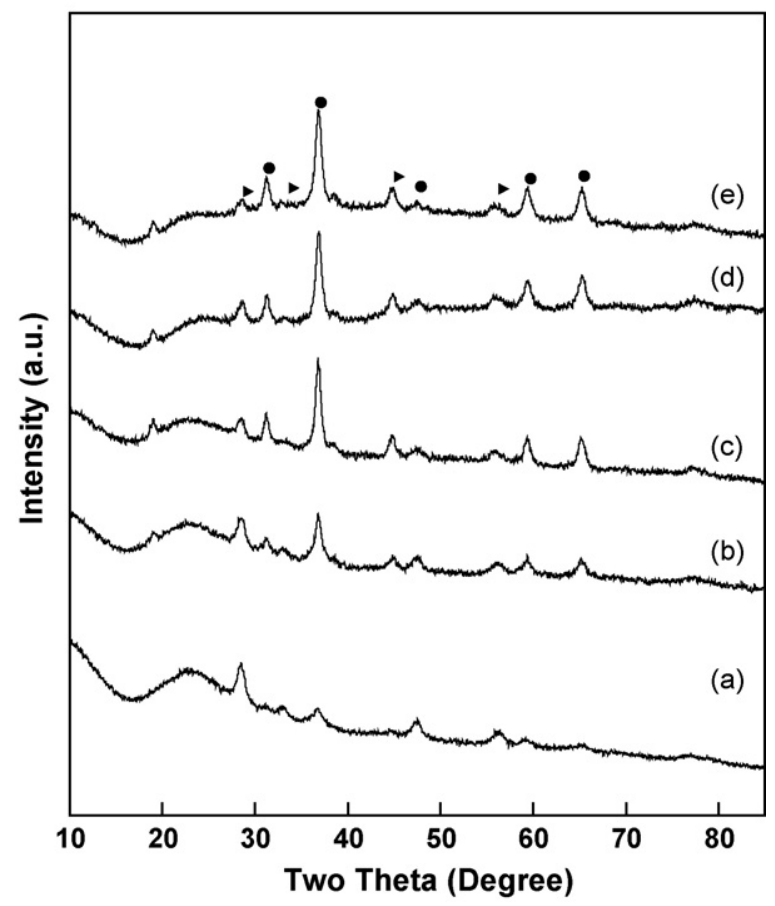

Fig. 2. X-ray diffraction patterns for Co- $x / y$ Ce-SBA-15 catalysts: (a) Co-10/8Ce-SBA-15; (b) Co-15/8Ce-SBA-15; (c) Co-20/8Ce-SBA-15; (d) Co20/15Ce-SBA-15 and (e) Co-20/25Ce-SBA-15. (A) $\mathrm{Co}_{3} \mathrm{O}_{4} ;(\bullet) \mathrm{CeO}_{2}$. 


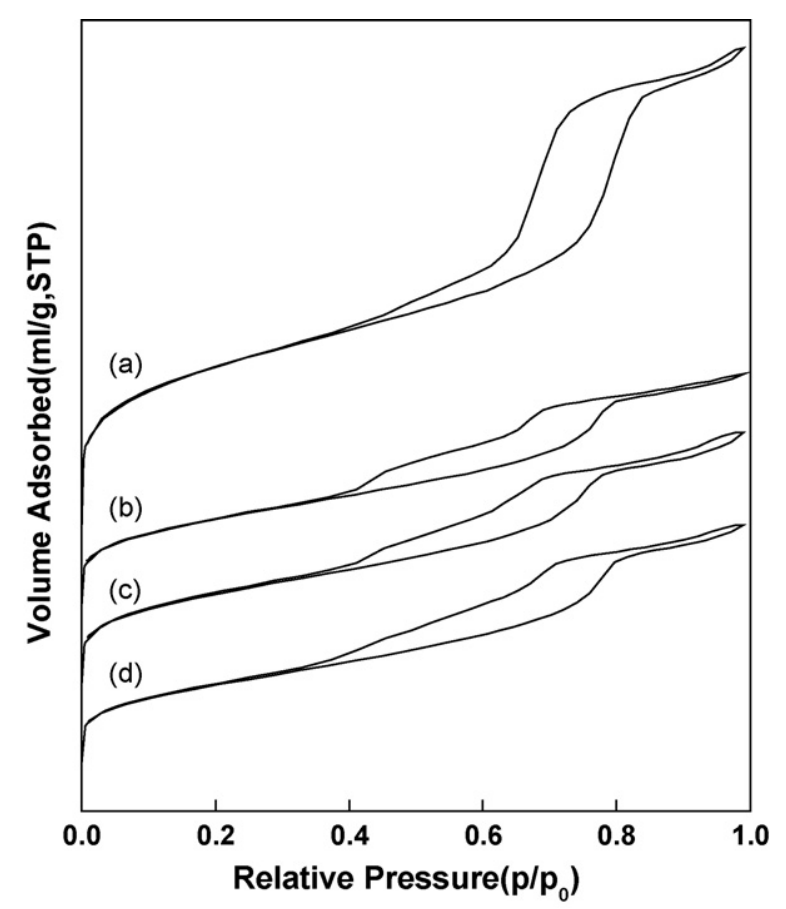

Fig. 3. Nitrogen adsorption/desorption isotherm of (a) 8Ce-SBA-15, and its modified catalysts with different cobalt loadings: (b) $10 \%$, (c) $15 \%$ and (d) $20 \%$.

behavior indicates the coexistence of open and partially closed mesopores. A peculiar two-step behavior is observed on the hysteresis loop of Co supported catalysts. The open mesopores behave as usual and produce the first step hysteresis loop on the desorption branch that ends near $P / P_{0}=0.6$, and the partially blocked mesopores are associated with the second step hysteresis loop which ends near $P / P_{0}=0.4$. The two-step hysteresis loop indicates that cobalt oxide particles have grown in the pores of the 8Ce-SBA-15 [24]. The physico-chemical properties of the investigated catalysts are given in Table 1 . For the Co- $x / 8 \mathrm{Ce}-\mathrm{SBA}-15$ samples, an increase in Co loading from 10 to $20 \%$, yielded in a decrease of the specific surface area $\left(S_{\mathrm{BET}}\right)$ and pore volume $\left(V_{\mathrm{p}}\right)$ from 584 to $529 \mathrm{~m}^{2} / \mathrm{g}$ and from 0.72 to $0.63 \mathrm{~cm}^{3} / \mathrm{g}$, respectively. This may be attributed to the micropore block by cobalt loading on the mesoporous surface. Comparing Ce-SBA-15 and Co/Ce-SBA-15, it was further found that the cobalt loading significantly reduces the specific surface area and porous size $\left(D_{\mathrm{p}}\right)$ but increases wall thickness $(w)$, which further confirms cobalt dispersion on the mesoporous surface. For the Ce-SBA- 15 support materials, the $S_{\mathrm{BET}}$ decreased from 912 to $797 \mathrm{~m}^{2} / \mathrm{g}$ with no obvious changes in $V_{\mathrm{p}}$ and $D_{\mathrm{p}}$ with the increase of cerium content. This indicates that cerium directly influences the microporous structure in framework.

DRS spectra in the UV-vis region of 8Ce-SBA-15 and corresponding cobalt modified catalysts Co-10/8Ce-SBA-15 and Co-20/8Ce-SBA-15 are shown in Fig. 4. The adsorption peaks centered at $300 \mathrm{~nm}$ were observed in all the samples. The peak is attributed to the metal charge transfer $\left(\mathrm{O}^{2-} \rightarrow \mathrm{Ce}^{4+}\right)$ of $\mathrm{CeO}_{2}$ clusters [25], which is in agreement with the results obtained from XRD patterns. For Co/Ce-SBA-15, there appear to be two new adsorption peaks at 380 and $700 \mathrm{~nm}$, which are indicative of $\mathrm{Co}_{3} \mathrm{O}_{4}$ clusters [26]. With the increase in cobalt loading, these two peaks become stronger. Characteristic peaks attributing to $\mathrm{Co}$ (II) are not observed in Fig. 4, which indicates that $\mathrm{Co}_{3} \mathrm{O}_{4}$ is the predominant phase when the cobalt loading is high [27]. Besides the previously mentioned peaks, an adsorption peak centered at ca. $230 \mathrm{~nm}$ can also be observed for all the samples. According to Ref. [28], the authors have attributed the band to the presence of the $\mathrm{NO}_{3}{ }^{-}$ions inside the support pores.

\subsection{Catalytic testing of $\mathrm{Co} / \mathrm{Ce}-\mathrm{SBA}-15$}

The catalytic performance of Co- $x / y$ Ce-SBA- 15 catalysts in the oxidation of benzene is listed in Table 2 . All the catalysts tested show high catalytic performance and can achieve $90 \%$ benzene conversion below $340{ }^{\circ} \mathrm{C}$. For the 


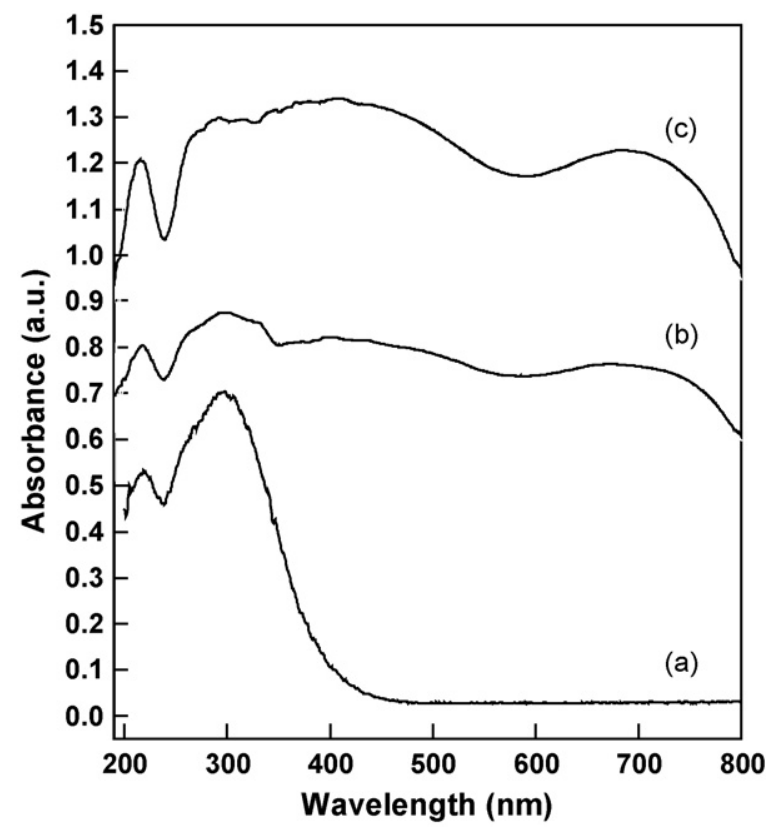

Fig. 4. UV-vis adsorption spectra of (a) 8Ce-SBA-15 and Co supported catalysts (b) Co-10/8Ce-SBA-15 and (c) Co-20/8Ce-SBA-15.

Co- $x / 8 \mathrm{Ce}-\mathrm{SBA}-15$ catalysts, the catalytic activities increase with an increase in cobalt loading. Co-10/8Ce-SBA-15 showed the poorest catalytic performance, with $T_{10}$ (the temperature at which the benzene conversion reached $10 \%$ ) of about $255^{\circ} \mathrm{C}$ and $T_{90}$ (the temperature at which the benzene conversion reached $90 \%$ ) of $340{ }^{\circ} \mathrm{C}$. While for Co-20/ $8 \mathrm{Ce}-\mathrm{SBA}-15, T_{10}$ and $T_{90}$ were about 245 and $300{ }^{\circ} \mathrm{C}$, respectively. On the other hand, Co-20/yCe-SBA-15 exhibits an obvious enhancement of catalytic activity with an increase in cerium content in the supports, which can be referred in Table 2. Particularly at $280{ }^{\circ} \mathrm{C}$, the conversion of benzene increased significantly from 50 to $95 \%$ as shown in Fig. 5. Table 2 also shows the catalytic performance of $\mathrm{Co} / \mathrm{CeO}_{2} / \mathrm{SBA}-15, \mathrm{Co} / \mathrm{CeO}_{2} / \mathrm{Al}_{2} \mathrm{O}_{3}$ on benzene deep oxidation. It was observed that these catalysts are less active than the Co-10/8Ce-SBA-15 catalysts.

As shown in Table 1 , the $S_{\mathrm{BET}}, V_{\mathrm{p}}$ and $D_{\mathrm{p}}$ of $\mathrm{CeO}_{2} / \mathrm{SBA}-15$ are much lower than that of $8 \mathrm{Ce}-\mathrm{SBA}-15$. This may be ascribed to the blockage of the support pores by $\mathrm{CeO}_{2}$, which can be observed in the impregnated sample [29]. While for 8Ce-SBA-15 synthesized by the direct hydrothermal method, $\mathrm{CeO}_{2}$ was better dispersed, which is supported by the XRD patterns in Fig. 6. The $S_{\mathrm{BET}}, V_{\mathrm{p}}$ and $D_{\mathrm{p}}$ of $\mathrm{CeO}_{2} / \mathrm{Al}_{2} \mathrm{O}_{3}$ are the smallest among all the supports tested. By comparing $\mathrm{CeO}_{2} / \mathrm{SBA}-15, \mathrm{CeO}_{2} / \mathrm{Al}_{2} \mathrm{O}_{3}$ and $8 \mathrm{Ce}-\mathrm{SBA}-15$, it was found that $8 \mathrm{Ce}-\mathrm{SBA}-15$ has a higher specific surface area that makes it an ideal candidate for use as a catalyst support.

The Ce-SBA-15 supported cobalt catalysts showed good catalytic performance in the catalytic deep oxidation of benzene. The increase in cerium content in the support significantly increased the catalytic activity of Co/Ce-SBA-15.

Table 2

Benzene oxidation activities over Co- $x / y \mathrm{Ce}-\mathrm{SBA}-15$ catalysts

\begin{tabular}{llll}
\hline Catalysts & $T_{10}$ & $T_{50}$ & $T_{90}$ \\
\hline Co-20/25Ce-SBA-15 & 220 & 260 & 275 \\
$\mathrm{Co}-20 / 15 \mathrm{Ce}-\mathrm{SBA}-15$ & 220 & 265 & 300 \\
$\mathrm{Co}-20 / 8 \mathrm{Ce}-\mathrm{SBA}-15$ & 245 & 280 & 300 \\
$\mathrm{Co}-15 / 8 \mathrm{Ce}-\mathrm{SBA}-15$ & 245 & 300 & 316 \\
$\mathrm{Co}-10 / 8 \mathrm{Ce}-\mathrm{SBA}-15$ & 255 & 319 & 340 \\
$\mathrm{Co} / \mathrm{CeO}_{2} / \mathrm{SBA}_{-15}$ & 270 & 340 & 372 \\
$\mathrm{Co} / \mathrm{CeO}_{2} / \mathrm{Al}_{2} \mathrm{O}_{3}$ & 300 & 355 & 390 \\
\hline
\end{tabular}




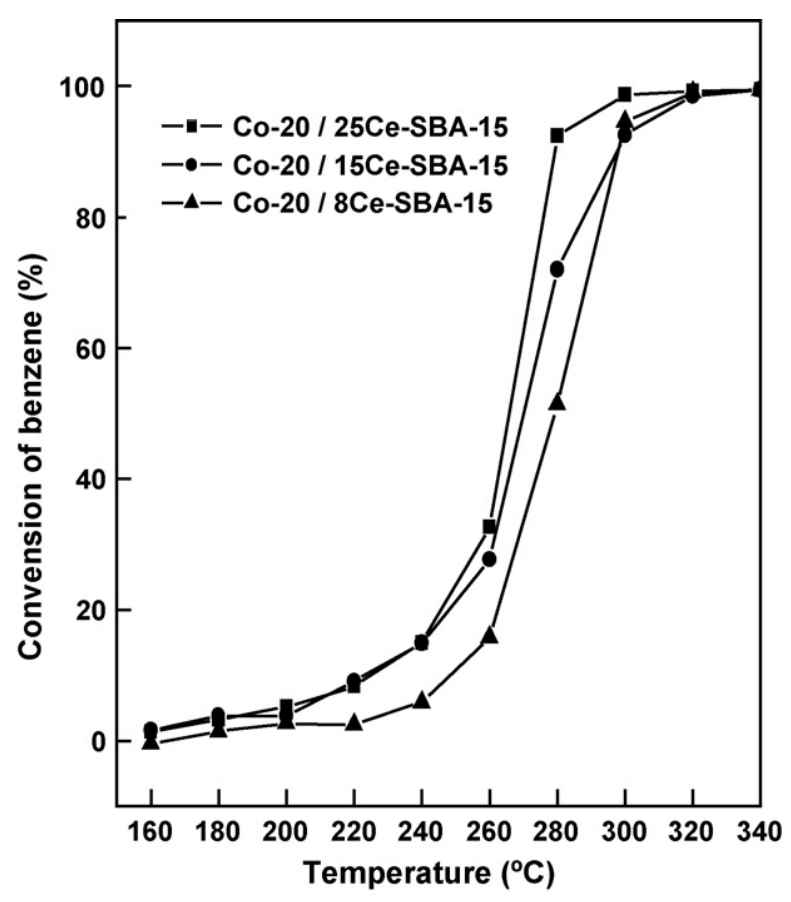

Fig. 5. Conversion curves of benzene oxidation over Ce-SBA-15 supported cobalt oxide catalysts.

Thus, there may exist a synergy effect between the cobalt and cerium ions [4,30]. Taking into consideration previous reported results [31,32], we postulate that this increase in catalytic activity is due to a higher reducibility of cobalt oxides and the increase in the amount of metallic atoms on the surface caused by the increase of cerium added. Detailed investigation of the interaction between the cobalt and cerium is still in progress.

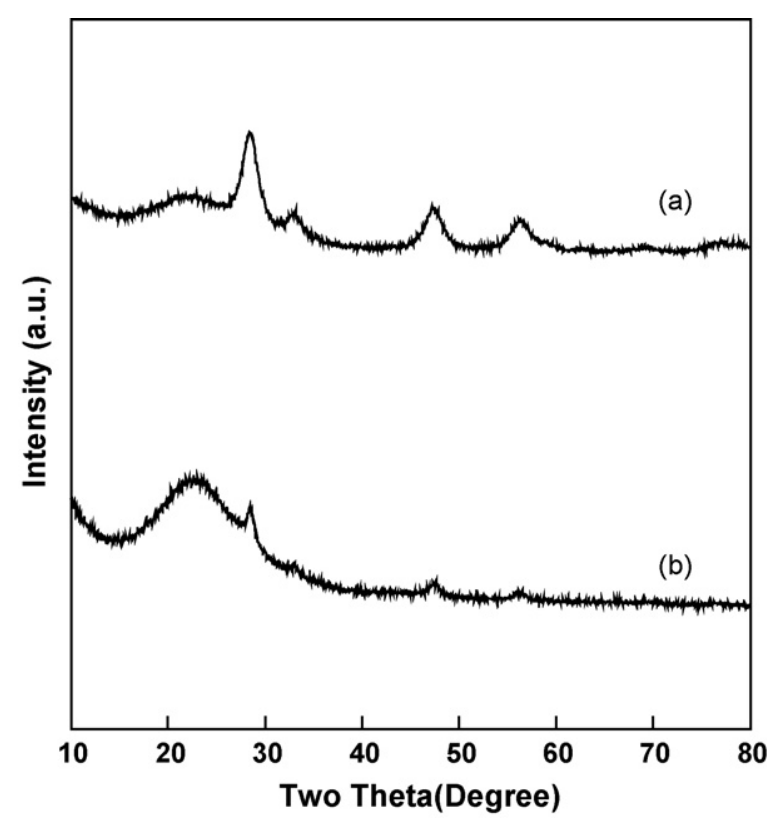

Fig. 6. XRD patterns of (a) $\mathrm{CeO}_{2} / \mathrm{SBA}-15$ and (b) $8 \mathrm{Ce}-\mathrm{SBA}-15$ synthesized at $\mathrm{pH} 2.0$. 


\section{Conclusions}

Ce-SBA-15 is used as a support for supported cobalt catalyst for the catalytic deep oxidation of benzene for the first time. On comparing with $\mathrm{CeO}_{2} / \mathrm{SBA}-15$ prepared by an impregnation method, Ce-SBA- 15 material synthesized by a direct hydrothermal method appears more suitable for preparing supported cobalt catalysts with high activity. The high surface area and mesoporosity of Ce-SBA-15 favors the dispersion of $\mathrm{Co}_{3} \mathrm{O}_{4}$. These Co/Ce-SBA- 15 catalysts show good catalytic performance in the oxidation of benzene, which is probably due to a synergy effect between the cobalt and cerium ions.

\section{Acknowledgements}

National Basic Research Program of China (2004CB719500), High Technology Research and Development Program of China (2006AA06A310) and National Science Fund for Distinguished Young Scholars (20725723) are gratefully acknowledged.

\section{References}

[1] S. Vetrivel, A. Pandurangan, J. Mol. Catal. A: Chem. 227 (2005) 269.

[2] V. Părvulescu, Cr. Tablet, C. Anastasescu, B.L. Su, Catal. Today 93-95 (2004) 307.

[3] A. Martínez, C. López, F. Márquez, I. Díaz, J. Catal. 220 (2003) 486.

[4] X. Xu, J. Li, Z. Hao, W. Zhao, C. Hu, Mater. Res. Bull. 41 (2006) 406.

[5] J. Li, X. Xu, Z. Hao, W. Zhao, J. Porous. Mater., doi:10.1007/s10934-007-9119-1.

[6] A.Y. Khodakov, A. Griboval-Constant, R. Bechara, V.L. Zholobenko, J. Catal. 206 (2002) 230.

[7] A.Y. Khodakov, R. Bechara, A. Griboval-Constant, Stud. Surf. Sci. Catal. 142 (2002) 1133.

[8] A. Griboval, A.Y. Khodakov, R. Bechara, V.L. Zholobenko, Stud. Surf. Sci. Catal. 144 (2002) 609.

[9] D. Zhao, J. Feng, Q. Huo, N. Melosh, G.H. Fredrickson, B.F. Chmelka, G.D. Stucky, Science 279 (1998) 548.

[10] D.Y. Zhao, Q.S. Huo, J.L. Feng, B.F. Chmelka, G.D. Stucky, J. Am. Chem. Soc. 120 (1998) 6024.

[11] V. Parvulescu, C. Constantin, B.L. Su, J. Catal. Mol. A: Chem. 202 (1-2) (2003) 171.

[12] A. Trovarelli, C.de. Leitenburg, M. Boaro, G. Dolcetti, Catal. Today 50 (1999) 353.

[13] C. Li, Q. Xin, J. Phys. Chem. 96 (19) (1992) 7714.

[14] A. Martínez-Arias, M. Fernández-García, O. Gálvez, J.M. Coronado, J.A. Anderson, J.C. Conesa, J. Soria, G. Munuera, J. Catal. 195 (2000) 207.

[15] X. Wang, J.A. Rodriguez, J.C. Hanson, D. Gamarra, A. Martínez-Arias, M. Fernández-García, J. Phys. Chem. B 110 (2006) 428.

[16] P. Bera, K.C. Patil, V. Jayaram, G.N. Subbanna, M.S. Hegde, J. Catal. 196 (2000) 293.

[17] Q.G. Dai, X.Y. Wang, G.P. Chen, Y. Zheng, G.Z. Lu, Micropor. Mesopor. Mater. 100 (2006) 268.

[18] M.N. Timofeeva, S.H. Jhung, Y.K. Hwang, D.K. Kim, V.N. Panchenko, M.S. Melgunov, Y.A. Chesalov, J.S. Chang, Appl. Catal. A 317 (2007) 1.

[19] W. Shen, X. Dong, Y. Zhu, H. Chen, J. Shi, Micropor. Mesopor. Mater. 85 (2005) 157.

[20] S.S. Bhoware, A.P. Singh, J. Mol. Catal. A: Chem. 266 (2007) 118.

[21] S. Villain, J. Cabané, P. Knauth, Sci. Mater. 38 (1998) 1003.

[22] K.S.W. Sing, D.H. Everett, R.A.W. Haul, L. Moscou, R.A. Pierotti, J. Rouquerol, T. Siemieniewska, Pure Appl. Chem. 57 (1985) 603.

[23] P.I. Ravikovitch, A.V. Neimark, Langmuir 18 (2002) 9830.

[24] A.H. Jansen, C.M. Yang, Y. Wang, F. Schüth, A.J. Koster, K.P. Jong, J. Phys. Chem. B 107 (2003) 10552.

[25] Z. Li, M. Flytzani-Stephanopoulos, J. Catal. 182 (1999) 313.

[26] R.L. Jacono, A. Cimino, G.C.A. Schuit, Gazz. Chim. Ital. 103 (1973) 1281.

[27] J. Panpranot, S. Kaewkun, P. Praserthdam, J.G. Goodwin, Catal. Lett. 91 (2003) 95.

[28] Th. Ataloglou, J. Vakros, K. Bourikas, Ch. Fountzoula, Ch. Kordulis, A. Lycourghiotis, Appl. Catal. B: Environ. 57 (2005) 299.

[29] B.M. Reddy, I. Ganesh, E.P. Reddy, J. Phys. Chem. B 101 (1997) 1769.

[30] L.F. Liotta, G.Di. Carlo, G. Pantaleo, A.M. Venezia, G. Deganello, Appl. Catal. B: Environ. 66 (2006) 217.

[31] G.R. Moradi, M.M. Basir, A. Taeb, A. Kiennemann, Catal. Commun. 4 (2003) 27.

[32] A. Feller, M. Claeys, E. van Steen, J. Catal. 185 (1999) 12. 